\title{
Fabrication and Test of LARP Technological Quadrupole Models of TQC Series
}

\author{
R.C. Bossert, G. Ambrosio, N. Andreev, E. Barzi, G. Chlachidze, S. Feher, V.S. Kashikhin, V.V. \\ Kashikhin, M. Lamm, A. Nobrega, I. Novitski, D. Orris, M. Tartaglia, A.V. Zlobin, S. Caspi, D. \\ Dietderich, P. Ferracin, A.R. Hafalia, G. Sabbi, A. Ghosh, P. Wanderer
}

\begin{abstract}
In support of the development of a large-aperture Nb3Sn superconducting quadrupole for the Large Hadron Collider (LHC) luminosity upgrade, several two-layer technological quadrupole models of TQC series with $90 \mathrm{~mm}$ aperture and collar-based mechanical structure have been developed at Fermilab in collaboration with LBNL. This paper summarizes the results of fabrication and test of TQC02a, the second TQC model based on RRP Nb3Sn strand, and TQC02b, built with both MJR and RRP strand. The test results presented include magnet strain and quench performance during training, as well as quench studies of current ramp rate and temperature dependence from $1.9 \mathrm{~K}$ to $4.5 \mathrm{~K}$.
\end{abstract}

Index Terms - LARP, LHC, Nb3Sn, quadrupole magnet, collars, quench.

\section{INTRODUCTION}

$\mathrm{H}$ IGH gradient Nb3Sn quadrupole models are being built at Fermilab and LBNL in an attempt to establish a design for an eventual luminosity upgrade at the LHC, within the framework of the US LHC Accelerator Research Program (LARP) [1]. A structure with aluminum shell (TQS) is being developed at LBNL [2]-[5] while a collar-based design with stainless steel shell (TQC) is being explored at Fermilab [6][8]. Five TQC models have been built and tested to date. This paper provides a brief overview of the first three models and describes in detail the fabrication experience and test results of the two most recent ones. Comparisons are made between all the models in the series.

\section{MAgnet Design}

\section{A. Structure}

TQC models contain a laminated collar assembly, laminated yoke and stainless steel skin as shown in Fig. 1. Structural details have been previously presented [6], [8].

Manuscript received 19 August 2008. This work was supported by the U.S. Department of Energy.

R.C. Bossert, G. Ambrosio, N. Andreev, E. Barzi, G. Chlachidze, S. Feher, V.S.Kashikhin, V.V. Kashikhin, M.J. Lamm, F. Nobrega, I. Novitski, D. Orris, M. Tartaglia, and A.V. Zlobin are with Fermi National Accelerator Laboratory, P.O. Box 500, Batavia, Il. USA Phone: 630-840-2867, fax: 630840-8079, e-mail: bossert@ fnal.gov).

S. Caspi, D.T. Dietderich, P Ferracin, R. Hafalia and G.L. Sabbi are with Lawrence Berkeley National Laboratory, Berkeley, CA 94720 USA.

A. Ghosh and P. Wanderer are with Brookhaven National Laboratory, Upton, NY, 11973-5000 USAT.

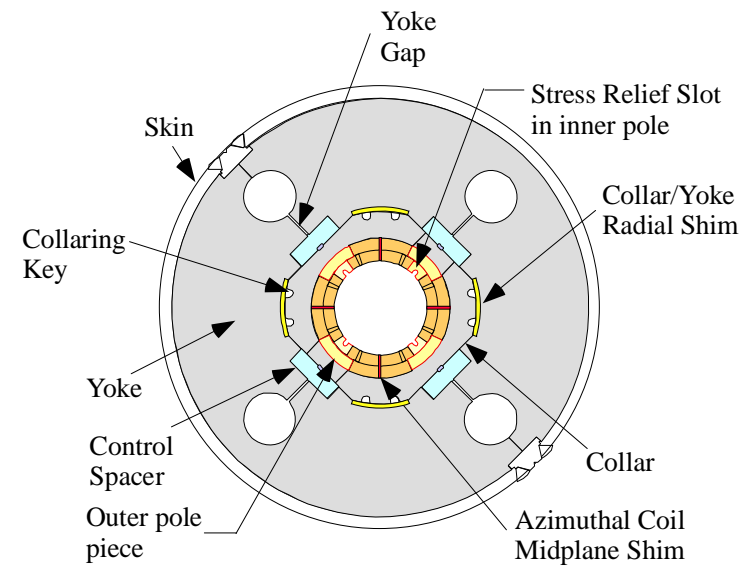

Fig. 1. TQC Structure and Shim System

The TQC yoke is surrounded by a $12 \mathrm{~mm}$ thick stainless steel skin. The skin of TQC01 was welded at two coil midplanes as shown in Fig. 1. Subsequent TQC models used a skin that was identical, but bolted on for ease of assembly and so shims could be changed to adjust preload if necessary.

\section{B. Preload}

Azimuthal preload was adjusted in each magnet, by changing the values of the coil mid-plane shims based on coil size measurements after impregnation and collar-yoke shims based on collared coil diameter measurements [9]. Peak preloads after coil collaring and final assembly are read by strain gauges on the inside surfaces of the coils and the metal coil poles. They are shown for all five TQC models in Table I. Absolute values of gauges from TQC01a and TQC02E were not reliable after cool-down, although strain curve shapes during excitation indicated that TQC01a showed evidence of unloading at full field, while TQC02E did not.

TABLE I PEAK PRELOADS IN TQC MODELS (MPA)

\begin{tabular}{cccccc}
\hline $\begin{array}{c}\text { Model } \\
\text { No. }\end{array}$ & $\begin{array}{c}\text { After } \\
\text { Collaring }\end{array}$ & $\begin{array}{c}\text { After } \\
\text { Assy }\end{array}$ & $\begin{array}{c}\text { After } \\
\text { Cool- } \\
\text { down }\end{array}$ & $\begin{array}{c}\text { At Max } \\
\text { field } \\
\mathbf{4 . 5 K}\end{array}$ & $\begin{array}{c}\text { At Max } \\
\text { Field } \\
\mathbf{1 . 9} \mathbf{K}\end{array}$ \\
\hline TQC01a & 19 & 49 & N/A & N/A & N/A \\
TQC01b & 39 & 106 & 118 & 39 & 26 \\
TQC02E & 54 & 108 & N/A & N/A & N/A \\
TQC02a & 62 & 138 & 88 & 27 & 27 \\
TQC02b & 43 & 120 & 62 & 26 & TBD \\
\hline \hline
\end{tabular}




\section{EXPERIENCE WITH PREVIOUS MODELS}

Experiences with TQC01a, TQC01b and TQC02E have been previously reported. A brief summary of their performance is included here with references to more detailed presentations.

\section{A. TQC01a and TQC01b}

TQC01a was the first TQC to be constructed [6], [7]. It contained low preload and strain gauges showed some unloading at the poles during excitation. It consequently reached only $71 \%$ of the SSL of the MJR cable at $4.5 \mathrm{~K}$, although reaching $85 \%$ at $1.9 \mathrm{~K}$.

TQC01b [8] contained two coils previously used in TQC01a and two coils used in TQS01a [3]. The magnet was assembled with higher coil azimuthal preload and consequently reached higher currents at $4.5 \mathrm{~K}$ than TQC01a. At both 4.5 and $1.9 \mathrm{~K}$, TQC01b was limited by the coils previously tested in TQS01a at about the same level of short sample limit.

\section{B. TQC02E}

TQC02E [8] used coils previously tested in TQS02a [4]. Collared preload was increased with respect to TQC01b but final yoked preload was kept the same. Quench performance was approximately equivalent to TQC02a at both temperatures, reaching $87 \%$ of its short sample limit at $4.5 \mathrm{~K}$ confirming similar performance in both TQS and TQC structures when using the same coils. Subsequently, the same coils were removed and tested in two more TQS models [5], and performed at the same level, demonstrating that both the collaring and de-collaring processes can be completed without coil degradation.

\section{TQC02A CONSTRUCTION AND PERFORMANCE}

\section{A. Design Goals and Construction}

TQC02a coils were made of RRP cable with critical current of $13873 \mathrm{~A}$ at $4.5 \mathrm{~K}$ and $15361 \mathrm{~A}$ at $1.9 \mathrm{~K}$. Two coils (17 and 19) had been previously collared and de-collared while two (24 and 27) had never been pressed.

The primary design goal for TQC02a was to repeat or improve the performance of TQC02E with a new set of RRP coils. A secondary goal was to increase the preload in the collared state while maintaining the same final preload as TQC02E. The preload is increased during the yoking process by locally applying pressure at the mid-planes through the collar-yoke shim, thereby bending the coils. Since the coil cross section remains round during the collaring process, increasing the collared preload with respect to the increment applied by the yoke was thought to minimize bending in the coils and distortion in the cross section. The process of increasing the collared preload with respect to the final assembled value had already been begun in TQC02E, and continued in TQC02a (see the "after collaring" column in Table 1).

The design goal of higher collared preload of TQC02a and similar final assembled preload was achieved, as shown in Table I. Higher collared pressures in this magnet were confirmed by collar deflection measurements shown in Fig. 2.
An end load of approximately $14 \mathrm{kN}$ per end (support, but not significant compression) was applied, as was done in all previous TQC models.

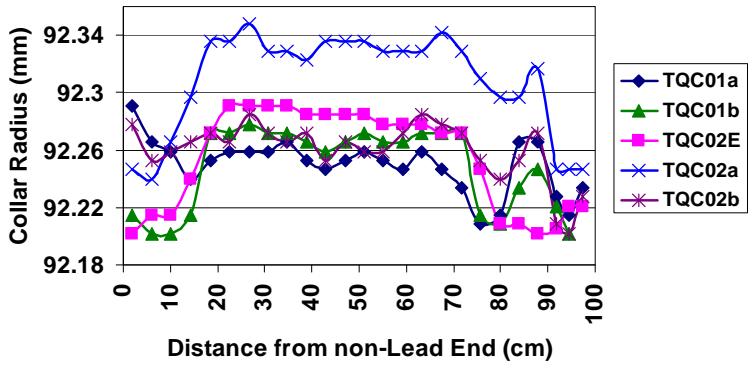

Fig. 2. Collar deflections after collaring in TQC models.

\section{B. Quench Performance}

TQC02a was tested in the Fermilab Vertical Magnet Test Facility (VMTF) in January and February of 2008.

Magnet training was done in liquid helium at both $4.5 \mathrm{~K}$ and $1.9 \mathrm{~K}$ and is shown in Fig. 3. The first quench was at $7245 \mathrm{~A}$, in coil 24. Slow training continued in coil 24 until the quench position changed to coil 27 , at a very specific spot near the return end of layer 1, at about 9250 A, about $67 \%$ of critical current. All subsequent quenches at $4.5 \mathrm{~K}$ remained at this precise current and position.

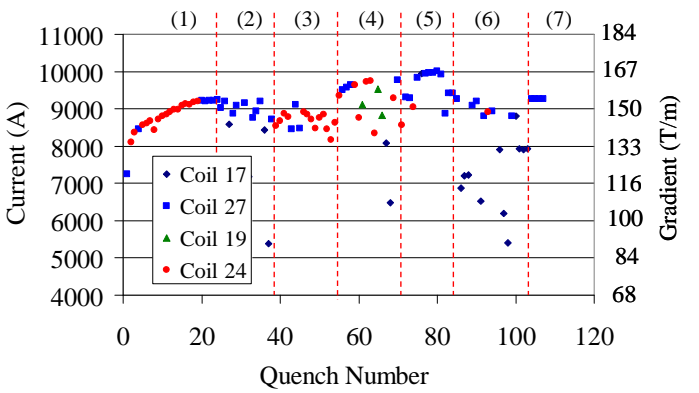

Fig. 3. TQC02a Quench History Key to zones: (1) 4.5K 20A/s, (2) $4.5 \mathrm{~K}$ ramp rate studies, (3) $1.9 \mathrm{~K} 20 \mathrm{~A} / \mathrm{s}$, (4) $1.9 \mathrm{~K}$ ramp rate studies, (5) Temp Dependence studies, (6) 4.5K ramp rate studies, (7) 4.5K $20 \mathrm{~A} / \mathrm{s}$

Training at $1.9 \mathrm{~K}$ followed a pattern similar to that in previous TQC and TQS models with RRP cable. Current at the training ramp rate of $20 \mathrm{~A} / \mathrm{s}$ did not increase from that at $4.5 \mathrm{k}$, and occurred primarily in low field areas of the outer layer. A slight increase occurred at higher ramp rates, but quenches still occurred in low field areas. It is likely that flux jump instabilities in the RRP cable is the source of this behavior.

Reasons for the poor quench performance of TQC02a at $4.5 \mathrm{~K}$ may be explained by local coil strain due to the aggressive collaring technique implemented for this magnet (high collared preload). In addition to the high collaring preload, TQC02a was made from two new coils and two previously pressed coils. Since the MOE of previously pressed coils is much higher than that of new coils, the strain sensitivity of the new coils would make them particularly sensitive to the higher stresses. All training quenches occurred in these two coils. A local flaw in coil 27 is another possible explanation. 
TQC02a contained the standard TQC instrumentation system. Strain gauges were placed at the bronze poles of TQC02b as well as on the inner coil surface. Control spacers, skin and end preload bolts were instrumented. Peak preload shown by the azimuthal gauges mounted to the bronze inner poles is shown in Table I. Preload at 1.9 was approximately the same as $4.5 \mathrm{~K}$, since current was only marginally higher. Control spacers remained loaded during cool-down, with load decreasing during excitation, as expected. Skin stress was 150 MPa after assembly, increased to 265 MPa during cool-down and remained approximately constant during excitation. End load was $17 \mathrm{kN}$ after assembly, remained constant during cool-down and increased during excitation to $77 \mathrm{kN}$, slightly higher than the increase in TQC01b.

\section{TQC02B CONSTRUCTION AND PERformance}

\section{A. Design Goals and Construction}

TQC02b had several goals. The first was to provide additional verification that successful operation could be achieved with the collaring process when returning to the lower collared preload used in earlier magnets. Preload levels during collaring were returned to the lower levels used in TQC01b. Another goal was to demonstrate conclusively that the erratic performance of the RRP coils at $1.9 \mathrm{~K}$ resulted from instabilities in the cable. To achieve this, two RRP coils and two MJR coils were used, configured as shown in Fig. 4. At $1.9 \mathrm{~K}$, quench protection heaters were to be used to heat the outer layer and study the instabilities in the RRP cable, as was previously done at FNAL in LM02 [10]. A third goal was to measure the temperature margin of MJR vs. RRP coils by using small 25um thick stainless heaters at each junction between an RRP and MJR coil. This study is reported elsewhere [11].

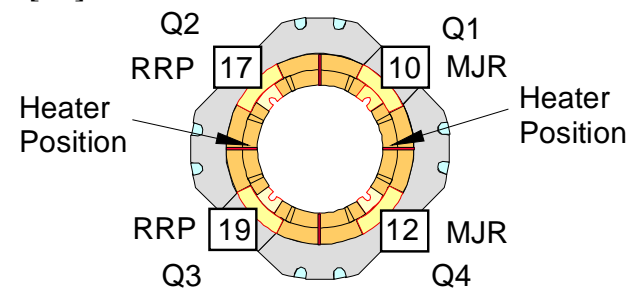

Fig. 4. TQC02b Coil and Heater Configuration

Preload levels during collaring were returned to the lower levels used in TQC01b (see Table 1.) The lower collared pressures in this magnet were confirmed by collar deflection measurements shown in Fig. 2.

\section{B. Performance}

TQC02b was tested in the Fermilab Vertical Magnet Test Facility (VMTF) in August of 2008. Test plan included quench performance and ramp rate studies at 4.5 and $1.9 \mathrm{~K}$, temperature margin studies at $4.5 \mathrm{~K}$ using the mid-plane heaters, and studies of the instabilities in the RRP coils at $1.9 \mathrm{~K}$ using the quench protection heaters to heat the outer layer.

Quench performance of TQC02b is shown in Fig. 5. Nominal current ramp rate for training quenches was $50 \mathrm{~A} / \mathrm{s}$. The first quench was $8420 \mathrm{~A}$, at $68 \%$ of the critical current limit of the conductor. Training proceeded in a slow but linear path with all quenches in coil 12 near the gap between straight section and end pole pieces at the return end of the inner layer. The plateau was reached at 10382A, about $84 \%$ of the critical current limit, similar to that of TQC01b. This performance provides additional evidence that the collaring process can be completed without degrading the cable. Magnet testing at $1.9 \mathrm{~K}$ is in progress.

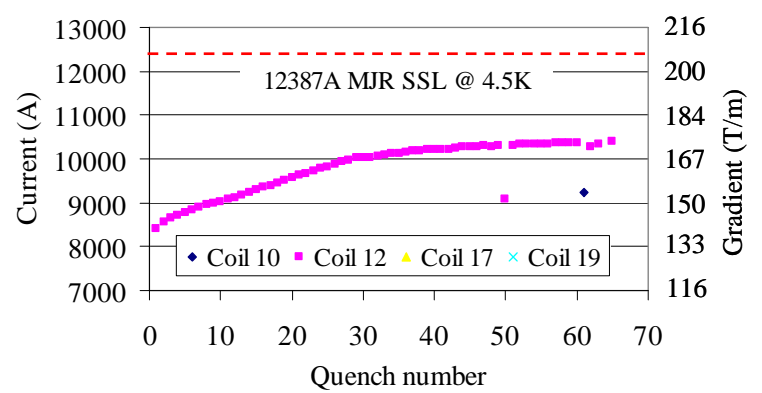

Fig. 5. TQC02b Quench Performance at 4.5K. The final 5 quenches (beginning with the quench in coil 10) were at higher ramp rates.

TQC02b was instrumented with the same strain gauge system as TQC02a. Coil gauges showed that preload decreased from 120 MPa to 65 MPa during cool down and did not unload during training at $4.5 \mathrm{~K}$. Control spacers remained loaded during cooldown, with load decreasing during excitation, as expected. Skin stress was $175 \mathrm{MPa}$ at assembly, increased to $260 \mathrm{MPa}$ during cool down and remained approximately constant during excitation, as expected. End load was $12 \mathrm{kN}$ after assembly, decreased slightly to $9 \mathrm{kN}$ during cool down and increased during excitation to $54 \mathrm{kN}$.

\section{EFFects Of CoIl DESIGN}

All coils in TQC models have the same cable size and cross section. However, they are made with several different features, some of which affect the performance of the magnet.

Cable may be manufactured by either the Modified Jelly Roll (MJR) the Rod Restack Process (RRP). Pole pieces may be either Bronze or Titanium alloy. Outer poles may or may not be potted into the cross section (some are mold released during impregnation so they can be removed later), and inner poles may contain slots as shown in Fig. 6 .

Table II lists the TQC models used and the coil styles used within them. Some models (TQC01b and TQC02b) contained more than one style. (Key: MJR $=\mathrm{J}, \mathrm{RRP}=\mathrm{R}, \mathrm{B}=$ Bronze, $\mathrm{T}$ $=$ Titanium, $\mathrm{P}=$ potted outer poles, $\mathrm{NP}=$ non-potted outer poles, $\mathrm{S}=$ inner coil pole slot, $\mathrm{N}=$ no pole slot).

TABLE II COILS USED IN TQC MODELS

\begin{tabular}{ccccc}
\hline \hline Model & Q1 & Q2 & Q3 & Q4 \\
\hline TQC01 & $\mathrm{J} / \mathrm{B} / \mathrm{NP} / \mathrm{S}$ & $\mathrm{J} / \mathrm{B} / \mathrm{NP} / \mathrm{S}$ & $\mathrm{J} / \mathrm{B} / \mathrm{NP} / \mathrm{S}$ & $\mathrm{J} / \mathrm{B} / \mathrm{NP} / \mathrm{S}$ \\
TQC01b & $\mathrm{J} / \mathrm{B} / \mathrm{P} / \mathrm{N}$ & $\mathrm{J} / \mathrm{B} / \mathrm{NP} / \mathrm{S}$ & $\mathrm{J} / \mathrm{B} / \mathrm{P} / \mathrm{N}$ & $\mathrm{J} / \mathrm{B} / \mathrm{NP} / \mathrm{S}$ \\
TQC02E & $\mathrm{R} / \mathrm{T} / \mathrm{P} / \mathrm{N}$ & $\mathrm{R} / \mathrm{T} / \mathrm{P} / \mathrm{N}$ & $\mathrm{R} / \mathrm{T} / \mathrm{P} / \mathrm{N}$ & $\mathrm{R} / \mathrm{T} / \mathrm{P} / \mathrm{N}$ \\
TQC02a & $\mathrm{R} / \mathrm{B} / \mathrm{NP} / \mathrm{S}$ & $\mathrm{R} / \mathrm{B} / \mathrm{NP} / \mathrm{S}$ & $\mathrm{R} / \mathrm{B} / \mathrm{NP} / \mathrm{S}$ & $\mathrm{R} / \mathrm{B} / \mathrm{NP} / \mathrm{S}$ \\
TQC02b & $\mathrm{J} / \mathrm{B} / \mathrm{NP} / \mathrm{S}$ & $\mathrm{R} / \mathrm{B} / \mathrm{NP} / \mathrm{S}$ & $\mathrm{R} / \mathrm{B} / \mathrm{NP} / \mathrm{S}$ & $\mathrm{J} / \mathrm{B} / \mathrm{NP} / \mathrm{S}$ \\
\hline \hline
\end{tabular}




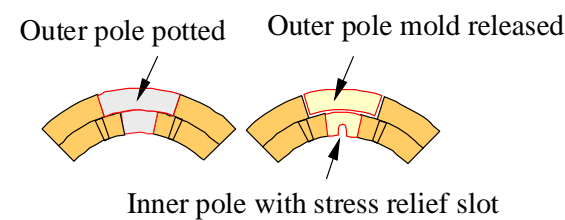

Fig. 6. TQC coil styles

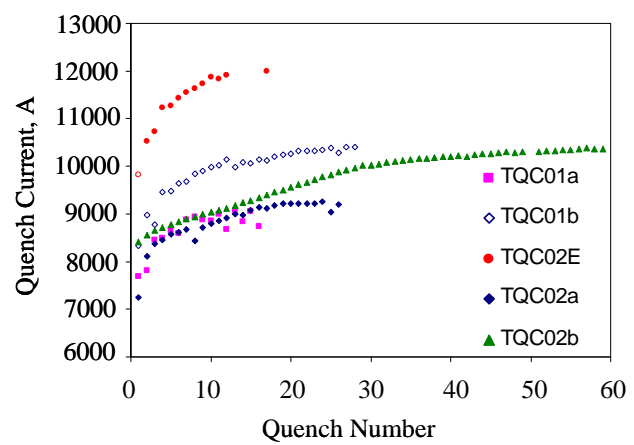

Fig. 7. Quench Performance of all TQ models at 4.5K. Training behavior of models with potted in parts and no pole slots show different training curve than models with pole slots and outer layer parts not potted.

Training behavior of all TQC models at $4.5 \mathrm{~K}$ is compared in Fig. 7. The rate of training in all coils with mold released outer poles and inner slots (TQC01a, TQC02a and TQC02b) display a distinct pattern (slow, linear increase), whereas coils with potted parts and no slots show a steeper rise and earlier plateau, even though all magnets used an identical structure. Also, pole gauges on TQC01b, which were mounted on coils without pole slots, show a slight increase in preload with cool down, while those on coils with pole slots show a decrease.

In addition, quench positions of adequately preloaded coils of the NP/S type have most quenches, and all late quenches, at the junction between the outer potted end pole section and non-potted section (see Fig. 8), while those with $\mathrm{P} / \mathrm{N}$ type have quenches distributed more evenly throughout the body [12]. Although these quenches occur in the inner layer while the junction between potted and non-potted parts is in the outer layer, high stresses during collaring as well as operation may occur in this area as a result of this discontinuity. Some indication of high stress on the inner layer in this area is evident on the inside surface of coils of the NP/S type.

Future TQ as well as LQ models will incorporate potted parts without pole slots, and therefore will not be subjected to possible stresses of this type.

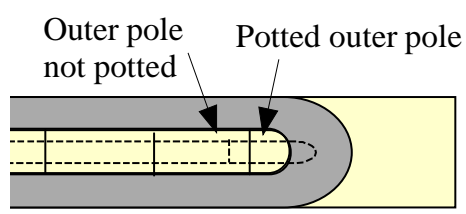

Fig. 8. Position of junction between potted and non-potted poles.

\section{CONCLUSION}

Five TQC models based on stainless steel collar and thick stainless steel skin support have been constructed and tested. Table IV lists their current, gradient and percentage of critical current reached. TQC01b, TQC02E, and TQC02b have demonstrated that the collaring process can produce magnets that perform reliably. Coils from both TQC02E and TQC01b have been reused in other magnets with little or no performance degradation. At $1.9 \mathrm{~K}$ quench performance of all RRP coils is limited by flux jump instabilities. TQC models of the non/potted with slot coil type show slower training and sometimes low quench plateau.

\section{TABLE IV TQC PERFORMANCE}

\begin{tabular}{ccccc}
\hline \hline Model & $\begin{array}{c}\text { SSL (I) } \\
4.5 \mathrm{~K} / 1.9 \mathrm{~K}\end{array}$ & $\begin{array}{c}\text { Quench } \\
\text { Plateau (I) } \\
4.5 \mathrm{~K} / 1.9 \mathrm{~K}\end{array}$ & \% of SSL & $\begin{array}{c}\text { Gradient } \\
(\mathrm{T} / \mathrm{m}) \\
4.5 \mathrm{~K} / 1.9 \mathrm{~K}\end{array}$ \\
\hline TQC01a & $12745 / 14082$ & $9092 / 11950$ & $71 / 85$ & $154 / 200$ \\
TQC01b & $12378 / 13679$ & $10559 / 11957$ & $85 / 87$ & $178 / 200$ \\
TQC02E & $13873 / 15361$ & $12004 / 11818$ & $87 / 77$ & $201 / 199$ \\
TQC02a & $13873 / 15361$ & $9251 / 10009$ & $67 / 65$ & $156 / 168$ \\
TQC02b & $12378 / 13679$ & $10382 /$ TBD & $84 / \mathrm{TBD}$ & $175 / \mathrm{TBD}$ \\
\hline \hline
\end{tabular}

Models have been shown to have preloads and stresses within the internal components that are in agreement with our simulations. Construction of four new coils based on more stable RRP 108/127 strand for the third TQ generation has begun. These coils will be tested first in the TQS structure (TQS03a), then in the TQC structure (TQC03E) in 2009. The goal of these tests is to improve magnet quench performance at both 4.5 and $1.9 \mathrm{~K}$

\section{REFERENCES}

[1] S.A. Gourlay, et al, "Magnet R\&D for the US LHC Accelerator Research Program (LARP)", IEEE Transactions on Applied Superconductivity, Vol. 16, No 2, pp. 324-327, June 2006.

[2] S. Caspi, et al, "Design and Construction of TQS01, a $90 \mathrm{~mm} \mathrm{Nb}_{3} \mathrm{Sn}$ Quadrupole Model for LHC Luminosity Upgrade Based on a Key and Bladder Structure," IEEE Transactions on Applied Superconductivity, Vol. 16, No 2, pp. 358-361, June 2006.

[3] S. Caspi, et al, "Fabrication and Test of TQS01 - A 90mm Nb $\mathrm{N}_{3} \mathrm{Sn}$ Quadrupole Magnet for LARP," IEEE Transactions on Applied Superconductivity, Vol. 17, No 2, pp. 1122-1125, June 2007.

[4] S. Caspi, et al, "Test and Analysis of Technology Quadrupole Shell (TQS) Magnet Models for LARP”, IEEE Transactions on Applied Superconductivity, Vol. 18, No 2, pp. 179-183, June 2008.

[5] S. Caspi, et al, "Test Results of LARP Nb3Sn Quadrupole Magnets Using a Shell-based Support Structure”, 5LX04, presented at ASC 2008.

[6] R. C. Bossert, et al., "Development of TQC01, a 90mm Nb${ }_{3} \mathrm{Sn}$ Model Quadrupole for LHC Upgrade Based on SS Collar," in IEEE Transactions on Applied Superconductivity, Vol. 16, No 2, pp. 370-373, June 2006.

[7] S. Feher, et al, "Development and Test of LARP Technological Quadrupole (TQC) Magnet” IEEE Transactions on Applied Superconductivity, Vol. 17, No. 2, pp. 1126-1129, June 2007.

[8] R. C. Bossert, et al., "Development and Test of LARP Technological Quadrupole Models of TQC Series,” in IEEE Transactions on Applied Superconductivity, Vol. 18, No 2, pp. 175-178, June 2008.

[9] D. R. Chichili, et al., "Investigation of Cable Insulation and ThermoMechanical Properties of Epoxy Impregnated $\mathrm{Nb}_{3} \mathrm{Sn}$ Composite”, IEEE Transactions on Applied Superconductivity, v. 10, No. 1, March 2000, p.1317.

[10] G. Chlachidze, et al, "Quench Performance of a $4 \mathrm{~m}$ long $\mathrm{Nb}_{3} \mathrm{Sn}$ costheta dipole coil, 5LX03, presented at ASC 2008.

[11] V.V. Kashikhin, et al, "Temperature Margin Measurement in $\mathrm{Nb}_{3} \mathrm{Sn}$ Accelerator Magnets, 3LPH10, presented at ASC 2008.

[12] R. Bossert, et al, "Quench Positions in TQC models" Fermilab Technical Division Technical Memo TD-08-024. 